\title{
BARRIERS TO PARTICIPATION IN TOURISM IN THE DISABLED
}

\author{
KRZYSZTOF KAGANEK ${ }^{1 A}$, TADEUSZ AMBROŻYIB, DARIUSZ MUCHA' ${ }^{1 C}$, ADAM JURCZAKID, \\ AGATA BORNIKOWSKA ${ }^{2}$, ANDRZEJ OSTROWSKI ${ }^{1 B}$, RENATA JANISZEWSKA ${ }^{2}$, TERESA MUCHA ${ }^{3}$ \\ ${ }^{1}$ University of Physical Education in Krakow, Faculty of Tourism and Recreation, Department of Recreation \\ and Wellness ${ }^{a}$, Faculty of Physical Education and Sport, Institute of Sport ${ }^{b}$, Institute of Health Sciencesc, \\ Institute of Social Sciences ${ }^{d}$ \\ ${ }^{2}$ Kazimierz Pulaski University of Technology and Humanities in Radom, Faculty of Health Sciences and \\ Physical Culture, Department of Physical Culture \\ ${ }^{3}$ Podhale State College of Applied Sciences in Nowy Targ, Institute of Humanities, Social Sciences and Tourism
}

Mailing address: Dariusz Mucha, University of Physical Education in Krakow, Institute of Health Sciences, 78 Jana Pawła II Ave., 31-571 Krakow, tel.: +48 601482162, fax: +48 12683 11 21, e-mail: dariusz.mucha@awf.krakow.pl

\begin{abstract}
Introduction. Physical activity is critical to effective rehabilitation in people with disabilities and, consequently, is of high importance in their lives. However, participation of the disabled in physical activity, including tourism, is a much more complex issue than in the case in able-bodied individuals. Material and methods. This paper aims to fill the gap and familiarise the reader with barriers faced by the disabled who engage in tourism. The study group consisted of randomly selected 460 participants with certificates specifying the degree of their disability. The group included 55 (12\%) individuals with visual impairments, 203 (44.1\%) individuals with hearing impairments, and 202 (43.9\%) individuals with locomotor system disabilities. Results. The data derived from interviews made with people with physical dysfunctions, designed with a view to achieving the aims of the study, were used to develop logistic regression models. Conclusions. On average, the greatest and smallest numbers of barriers were reported by individuals with severe disabilities and those who had large families, respectively. Younger disabled people most often complained about the equipment barriers to participation in tourism. Older respondents were mostly challenged with social barriers. Of all the determinants analysed in the study, the perception of barriers to participation in tourism most often depended on the subjects' degree of disability.
\end{abstract}

Key words: disability, barriers to participation in tourism, logistic regression model

\section{Introduction}

Nowadays, tourism and active recreation are becoming increasingly popular among people with disabilities. This poses a challenge for organisations operating in the tourism market, particularly those that promote and prepare tourist events so that disabled individuals can also participate in tourism and active recreation. Tourism and recreation represent an important component of the rehabilitation of disabled people, contributing to the minimisation of the effects of limited physical mobility, and help them overcome their limitations and cope with disability-related complexes.

The international literature on the topic highlights that disability influences numerous aspects of life, including the possibility to participate in tourism. A great number of the disabled do not travel at all, while others are active tourists. However, the latter face numerous challenges. Kwai-sang You, McKercher, and Packer [1] are some authors who have discussed these problems. They unambiguously state that the literature on the subject does not present tourist experiences which result from empirical research, but focuses on generalisations that are detached from reality. At the same time, they argue that the development of the tourism market for the disabled is very often neglected and that the research studies in carried out this field in the early 1980s and 1990s were not continued. These authors used interviews as the most reliable methodology. They divided participants into individuals with limited mobility and those visually impaired. In order to capture practical experiences, they first conducted independent interviews with organisations established to support the disabled. The key information from these interviews helped identify a group of fundamental problems.

Disabled people who participate in tourism face a plethora of barriers. One of the most often quoted classifications of barriers making it difficult for the disabled to participate in tourism was proposed by Smith, who divided them into real, environmental, and interactive barriers [2] .

Real barriers result directly from the type of disability or are indirectly related to it (e.g. parents' or caretakers' overprotectiveness or inadequate education) and are originally internal. Smith listed the following real barriers: lack of knowledge, health-related problems, social ineptness, and physical and psychiatric dependency. The following barriers were included in the group of environmental barriers: attitude, architecture, ecology, transport, law, and regulations. Interactive barriers, on the other hand, are insufficient abilities to face the challenge and communication barriers.

Barriers limit the sense of freedom, personal control, and competence. A disabled person may interpret failures as their personal defeats, even though they were caused by external factors. This results in the withdrawal from participation or gener- 
ates negative feelings in the course of doing something or after it has been done. This also leads to a reduced sense of satisfaction and self-confidence. Tourism should be a way to escape from daily life and its problems, but very often disabled people face the same problems in new situations. Organising special trips for the disabled excludes them from the rest of society and limits the opportunities to choose various social roles.

The most frequent and common barriers to participation in tourism experienced by the community of people with disabilities in Poland include financial, social, psychological, organisational, equipment, and architectural barriers, as well as a lack of personnel and tourist offers [3]. The aim of this paper is to identify the determinants that affect the perception of particular barriers in tourism. This aim can be expressed in the form of the following research questions:

1. What are the determinants of the perception of barriers?

2. Do the barriers vary depending on the degree of disability?

\section{Material and methods}

A diagnostic survey was used to diagnose the factors which determine barriers to participation in tourism reported by people with disabilities. The method was adjusted to the aim of the study and included questions related to tourism practised by the disabled. Data were collected from 2012 to 2014 from interviews based on a questionnaire.

The study group consisted of randomly selected 460 participants with certificates confirming the degree of their disability. The group included 55 (12\%) individuals with visual impairments, 203 (44.1\%) individuals with hearing impairments, and 202 (43.9\%) individuals with locomotor system disabilities. The respondents were members of Polish organisations and centres for the disabled from the Lesser Poland, Silesian, Subcarpathian, and Łódzkie Provinces. The study group comprised 213 men (46.3\%) and 247 (53.7\%) women. Their mean age was $54.6 \pm$ 15.8 years and $53.2 \pm 15.2$ years for men and women, respectively. The difference between the mean age in the subgroups of men and women was statistically insignificant $(\mathrm{t}=1.02 ; \mathrm{p}=0.314)$.

The analysis of the determinants of reporting particular barriers and the design of adequate models was based on the financial, social, psychological, organisational, equipment, and architectural barriers, as well as the lack of personnel and tourist offers.

Sixteen demographic and social characteristics were taken into account as factors determining the choice of barriers. These included: place of residence, sex, marital status, number of children, education, degree of disability, membership in tourism organisations, tourist traditions in the family, help of other people, living with the family, progressing disability (not congenital or caused by an injury), type of dysfunction (impaired vision, hearing, or locomotor system), financial status, and age. An analysis of the related literature showed that these characteristics influence the choice of barriers to participation in tourism reported by the disabled.

Logistic regression was used for the statistical analysis to develop a model of the effect of specific characteristics on the choice of barriers reported by the disabled. The barriers to participation in tourism (determined using "Yes" or "No" answers) represented the dependent variables $(Y)$. The above 16 characteristics were used as independent variables $x=\left[1, x_{1}, \ldots, x_{16}\right]$ '.

The logistic regression model, which determines the likelihood of the choice of a barrier to participation in tourism depending on determinants $x_{1}, \ldots, x_{16}$, is given by the following equation:

$$
P(Y=l / \boldsymbol{x})=\frac{e^{\beta_{0}+\beta_{1} x_{1}+\ldots+\beta_{p} x_{p}}}{1+e^{\beta_{0}+\beta_{1} x_{1}+\ldots+\beta_{p} x_{p}}} .
$$

The Wald test was used to verify the coefficients of logistic regression $\beta_{\mathrm{j}}$ for $j=0, \ldots 16$. Based on the coefficient $\beta_{\mathrm{I}}$, the odds ratio, and its $95 \%$ confidence interval for $i$ of this feature was calculated. The stepwise elimination of features was employed to design a barrier selection model including only significant determinants.

\section{Results}

Table 1 presents the number of barriers to participation in tourism chosen by the disabled within particular categories of determinants. Each respondent was allowed to choose multiple barriers. The "Total number of barriers reported" column contains the number of barriers chosen by participants within a particular category of determinants. The next column, "Number of respondents", gives the number of people for each category. The number of barriers per person is also presented. The final row provides information about the mean age of study participants who reported the barriers.

Out of 8 barriers taken into consideration in the questionnaire, 1.35 barriers per person were reported on average in the group of disabled people examined in the study. The greatest number of barriers was chosen by people with severe disabilities (1.84 barriers per person). People with higher education chose, on average, 1.62 barriers per person, whereas the disabled who did not have any children chose 1.59 barriers per person. The fewest barriers were chosen by the respondents who had four or more children (1.07 barriers per person). The results are presented in Table 1.

With regard to the age of the study participants with disabilities, the youngest $(\mathrm{x}=46.5$ years old) participants tended to choose barriers related to equipment, whereas the oldest ones $(x=61.2$ years old) chose social barriers. The results are presented in Table 1.

The main barriers to participation in tourism most often chosen by the disabled were financial barriers (67.8\%), followed by organisational barriers $(29.1 \%)$. The least frequently chosen barrier was related to the lack of personnel $(2.2 \%)$. The results are presented in Table 2 .

The relations between the determinants and particular barriers to participation in tourism are illustrated in Table 3, which contains $\mathrm{p}$ values assigned to the statistical tests from the onedimensional statistical analysis. $P$ values $\leq 0.05$, which indicate statistically significant links between the determinants and the barriers, are written in bold.

Multivariate statistical analysis was also performed. Table 4 and Figures 1-8 present the results of the analysis.

The following factors influenced the perception of financial barriers to participation in tourism by study participants: living in a city (with more than 10,000 residents), young age, mild physical disability, and living with the family (Fig. 1).

The perception of social barriers is more often noticeable in disabled men with severe disabilities who had been raised in families without a tradition of engaging in tourism and were not living with their families at the time of the study (they lived alone or in nursing homes) (Fig. 2). 
Table 1. Number of respondents reporting particular types of barriers according to the categories of determinants and mean age of respondents who reported particular types of barriers

\begin{tabular}{|c|c|c|c|c|c|c|c|c|c|c|c|c|}
\hline \multirow{2}{*}{\multicolumn{2}{|c|}{ Determinants }} & \multicolumn{8}{|c|}{ Barriers (1 - Yes) } & \multirow{3}{*}{ 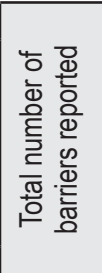 } & \multirow{3}{*}{ 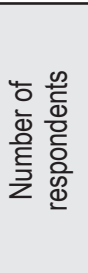 } & \multirow{3}{*}{ 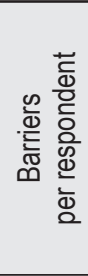 } \\
\hline & & \multirow{3}{*}{ 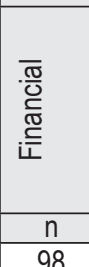 } & \multirow{3}{*}{ 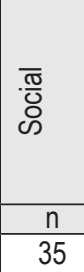 } & \multirow{3}{*}{ 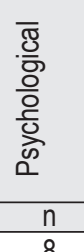 } & \multirow{3}{*}{ 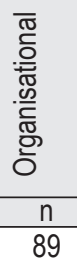 } & \multirow{3}{*}{ 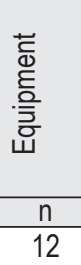 } & \multirow{3}{*}{ 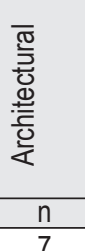 } & \multirow{3}{*}{ 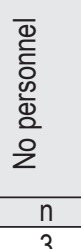 } & \multirow{2}{*}{ 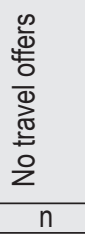 } & & & \\
\hline & & & & & & & & & & & & \\
\hline \multirow{3}{*}{ Place of residence } & Rural area & & & & & & & & 5 & 257 & 191 & 1.35 \\
\hline & Town & 50 & 6 & 6 & 9 & 4 & 4 & 1 & 5 & 85 & 69 & 1.23 \\
\hline & City & 164 & 16 & 18 & 36 & 14 & 11 & 6 & 15 & 280 & 200 & 1.40 \\
\hline \multirow{2}{*}{ Sex } & Male & 135 & 34 & 19 & 72 & 15 & 5 & 3 & 10 & 293 & 213 & 1.38 \\
\hline & Female & 177 & 23 & 13 & 62 & 15 & 17 & 7 & 15 & 329 & 247 & 1.33 \\
\hline \multirow{2}{*}{ Marital status } & Single & 123 & 28 & 15 & 59 & 9 & 8 & 4 & 9 & 255 & 187 & 1.36 \\
\hline & Married & 189 & 29 & 17 & 75 & 21 & 14 & 6 & 16 & 367 & 273 & 1.34 \\
\hline \multirow{5}{*}{ Number of children } & 0 & 78 & 17 & 10 & 32 & 9 & 3 & 2 & 6 & 157 & 99 & 1.59 \\
\hline & 1 & 77 & 5 & 8 & 26 & 5 & 4 & 3 & 6 & 134 & 100 & 1.34 \\
\hline & 2 & 102 & 12 & 10 & 34 & 8 & 13 & 3 & 8 & 190 & 154 & 1.23 \\
\hline & 3 & 46 & 21 & 3 & 39 & 8 & 2 & 2 & 5 & 126 & 93 & 1.35 \\
\hline & 4 & 9 & 2 & 1 & 3 & 0 & 0 & 0 & 0 & 15 & 14 & 1.07 \\
\hline \multirow{8}{*}{ Education } & No education & 2 & 7 & 0 & 12 & 1 & 0 & 0 & 0 & 22 & 15 & 1.47 \\
\hline & Primary & 20 & 8 & 3 & 11 & 2 & 1 & 0 & 0 & 45 & 37 & 1.22 \\
\hline & Vocational & 92 & 28 & 11 & 63 & 7 & 11 & 2 & 7 & 221 & 169 & 1.31 \\
\hline & Secondary general & 40 & 1 & 4 & 12 & 2 & 1 & 1 & 1 & 62 & 48 & 1.29 \\
\hline & Secondary vocational & 83 & 6 & 3 & 17 & 11 & 8 & 2 & 10 & 140 & 103 & 1.36 \\
\hline & Post-secondary & 19 & 1 & 1 & 4 & 0 & 0 & 0 & 2 & 27 & 20 & 1.35 \\
\hline & Incomplete higher & 21 & 3 & 2 & 4 & 2 & 0 & 2 & 3 & 37 & 26 & 1.42 \\
\hline & Higher & 35 & 3 & 8 & 11 & 5 & 1 & 3 & 2 & 68 & 42 & 1.62 \\
\hline \multirow{3}{*}{ Degree of disability } & Severe & 28 & 5 & 3 & 13 & 7 & 14 & 1 & 8 & 79 & 43 & 1.84 \\
\hline & Moderate & 131 & 43 & 15 & 87 & 9 & 4 & 4 & 6 & 299 & 227 & 1.32 \\
\hline & Mild & 153 & 9 & 14 & 34 & 14 & 4 & 5 & 11 & 244 & 190 & 1.28 \\
\hline & No & 136 & 31 & 16 & 70 & 7 & 14 & 4 & 12 & 290 & 214 & 1.36 \\
\hline Car ownership & Yes & 176 & 26 & 16 & 64 & 23 & 8 & 6 & 13 & 332 & 246 & 1.35 \\
\hline Membership in organisa- & No & 281 & 53 & 29 & 122 & 26 & 16 & 10 & 23 & 560 & 414 & 1.35 \\
\hline tions for the disabled & Yes & 31 & 4 & 3 & 12 & 4 & 6 & 0 & 2 & 62 & 46 & 1.35 \\
\hline Membership in tourist & No & 282 & 54 & 28 & 129 & 24 & 20 & 8 & 24 & 569 & 421 & 1.35 \\
\hline organisations & Yes & 30 & 3 & 4 & 5 & 6 & 2 & 2 & 1 & 53 & 39 & 1.36 \\
\hline Tourist traditions in the & No & 252 & 55 & 23 & 115 & 24 & 19 & 8 & 23 & 519 & 382 & 1.36 \\
\hline family & Yes & 60 & 2 & 9 & 19 & 6 & 3 & 2 & 2 & 103 & 78 & 1.32 \\
\hline Heln of other nenole & No & 225 & 39 & 22 & 86 & 22 & 19 & 6 & 22 & 441 & 325 & 1.36 \\
\hline Heip or otner people & Yes & 87 & 18 & 10 & 48 & 8 & 3 & 4 & 3 & 181 & 135 & 1.34 \\
\hline I iving with family & No & 62 & 38 & 7 & 85 & 3 & 8 & 2 & 1 & 206 & 149 & 1.38 \\
\hline Living vitu lanminy & Yes & 250 & 19 & 25 & 49 & 27 & 14 & 8 & 24 & 416 & 311 & 1.34 \\
\hline Progrocsina dicability & No & 134 & 24 & 14 & 48 & 19 & 15 & 7 & 16 & 277 & 179 & 1.55 \\
\hline riogressing ulsabinity & Yes & 178 & 33 & 18 & 86 & 11 & 7 & 3 & 9 & 345 & 281 & 1.23 \\
\hline & $\begin{array}{l}\text { Locomotor system } \\
\text { dysfunction }\end{array}$ & 142 & 21 & 5 & 73 & 13 & 7 & 5 & 9 & 275 & 202 & 1.36 \\
\hline Dysfunction type & Vision dysfunction & 123 & 33 & 22 & 51 & 11 & 13 & 3 & 13 & 269 & 203 & 1.33 \\
\hline & Hearing dysfunction & 47 & 3 & 5 & 10 & 6 & 2 & 2 & 3 & 78 & 55 & 1.42 \\
\hline Financial status & Good & 145 & 41 & 17 & 111 & 17 & 13 & 7 & 13 & 364 & 259 & 1.41 \\
\hline Financial status & Bad & 167 & 16 & 15 & 23 & 13 & 9 & 3 & 12 & 258 & 201 & 1.28 \\
\hline & & 312 & 57 & 32 & 134 & 30 & 22 & 10 & 25 & 622 & 460 & 1.35 \\
\hline Mean age of respond & is who reported barrier & 49.3 & 61.2 & 48.3 & 57.5 & 46.5 & 51.5 & 49.9 & 49.1 & - & 53.9 & - \\
\hline
\end{tabular}

Total in a row can be greater than total number of people in the last column. 
Table 2. Percentage of respondents reporting particular types of barriers according to the categories of determinants

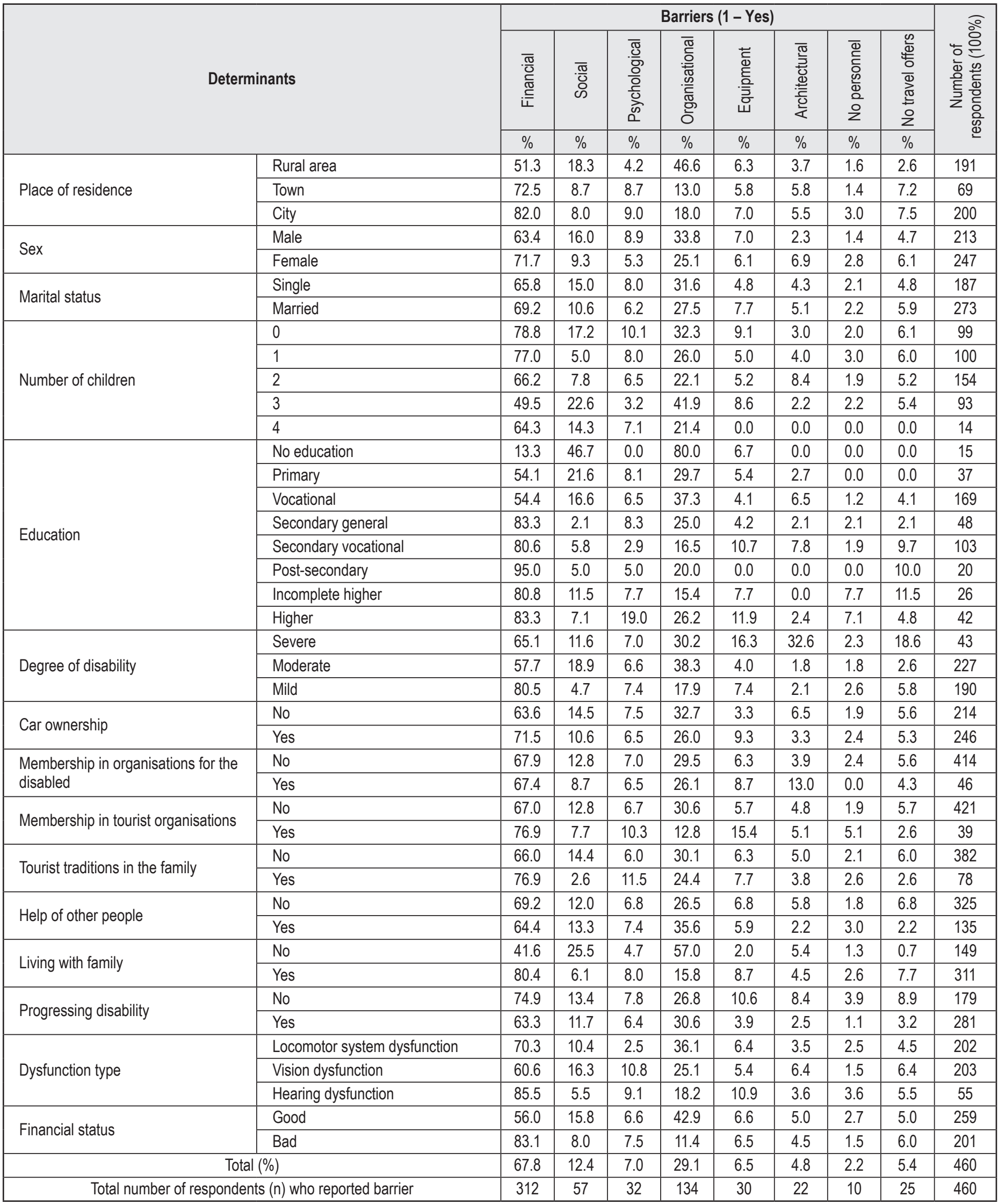

Total of $\%$ in a row does not equal $100 \%$ since respondents were allowed to choose multiple barriers. 
Table 3. The influence of determinants on the types of barriers reported: $p$ values

\begin{tabular}{|c|c|c|c|c|c|c|c|c|}
\hline \multirow[b]{2}{*}{ Determinants $(n=460)$} & \multicolumn{8}{|c|}{ Barriers (1 - Yes) } \\
\hline & 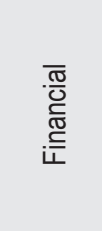 & $\begin{array}{l}\overline{\mathbb{T}} \\
\bar{O} \\
\mathscr{D}\end{array}$ & 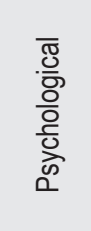 & 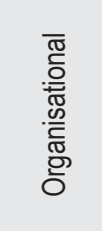 & 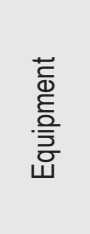 & 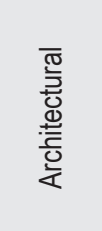 & 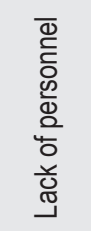 & 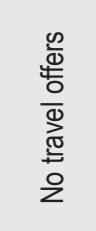 \\
\hline Place of residence & $<0.001$ & 0.005 & 0.144 & $<0.001$ & 0.926 & 0.636 & 0.566 & 0.080 \\
\hline Sex & 0.058 & 0.031 & 0.124 & 0.041 & 0.675 & 0.023 & 0.296 & 0.517 \\
\hline Marital status & 0.436 & 0.164 & 0.458 & 0.344 & 0.219 & 0.675 & 0.966 & 0.626 \\
\hline Number of children & $<0.001$ & $<0.001$ & 0.443 & 0.014 & 0.473 & 0.114 & 0.954 & 0.916 \\
\hline Education & $<0.001$ & $<0.001$ & 0.058 & $<0.001$ & 0.294 & 0.347 & 0.138 & 0.139 \\
\hline Degree of disability & $<0.001$ & $<0.001$ & 0.955 & $<0.001$ & 0.009 & $<0.001$ & 0.830 & $<0.001$ \\
\hline Car ownership & 0.067 & 0.203 & 0.683 & 0.115 & 0.008 & 0.099 & 0.676 & 0.879 \\
\hline Membership in organisations for the disabled & 0.947 & 0.423 & 0.903 & 0.632 & 0.529 & 0.006 & 0.286 & 0.732 \\
\hline Membership in tourist organisations & 0.204 & 0.352 & 0.397 & 0.019 & 0.019 & 0.915 & 0.186 & 0.408 \\
\hline Tourist traditions in the family & 0.059 & 0.004 & 0.081 & 0.309 & 0.646 & 0.671 & 0.785 & 0.220 \\
\hline Help of other people & 0.317 & 0.693 & 0.806 & 0.051 & 0.739 & 0.097 & 0.454 & 0.050 \\
\hline Living with family & $<0.001$ & $<0.001$ & 0.187 & $<0.001$ & 0.007 & 0.683 & 0.397 & 0.002 \\
\hline Progressing disability & 0.010 & 0.597 & 0.561 & 0.383 & 0.005 & 0.004 & 0.040 & 0.008 \\
\hline Dysfunction type & 0.001 & 0.050 & 0.003 & 0.008 & 0.342 & 0.350 & 0.576 & 0.688 \\
\hline Financial status & 0.001 & 0.011 & 0.707 & $<0.001$ & 0.967 & 0.787 & 0.377 & 0.655 \\
\hline Age & $<0.001$ & $<0.001$ & 0.036 & 0.001 & 0.007 & 0.467 & 0.416 & 0.117 \\
\hline
\end{tabular}

$\chi^{2}$ test or Student t-test.

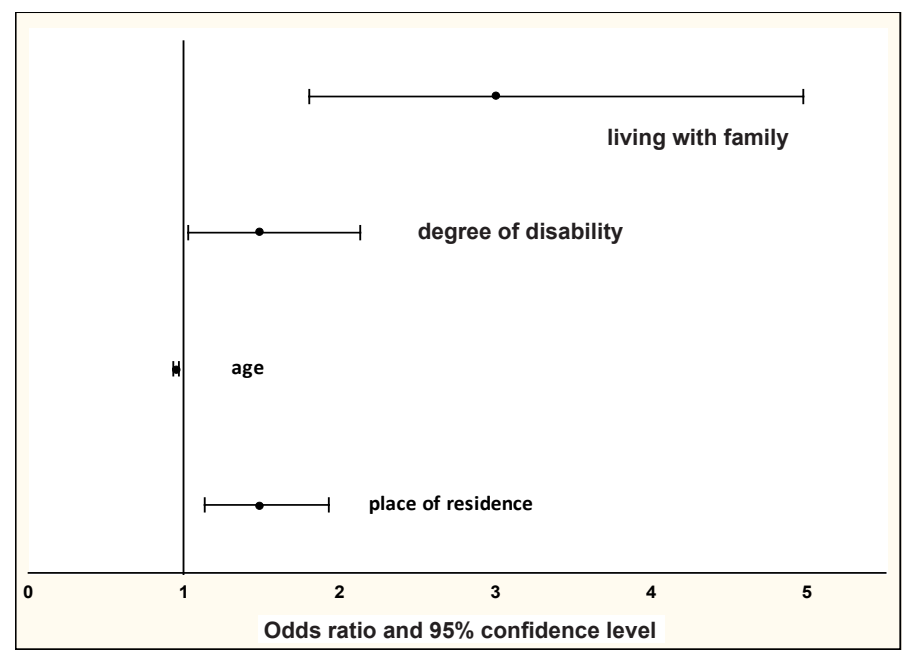

Figure 1. Financial barriers

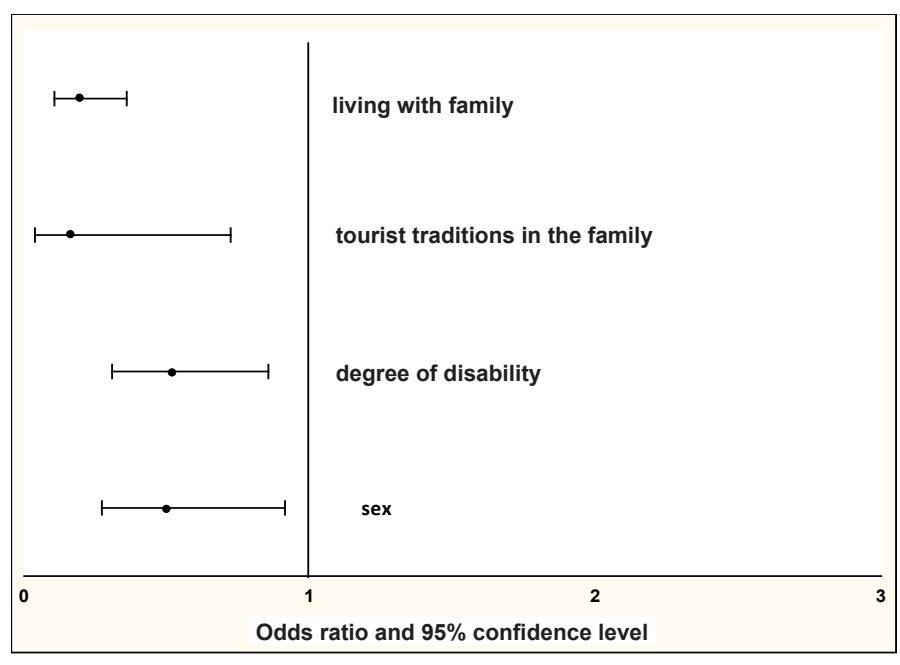

Figure 2. Social barriers 
Table 4. Determinants of the perception of barriers to participation in tourism reported by means of stepwise logistic regression

\begin{tabular}{|c|c|c|c|c|c|}
\hline \multirow{6}{*}{ Financial } & Constant $=-1.48$ & Place of residence & Age & Degree of disability & Living with family \\
\hline & Beta & 0.390 & -0.054 & 0.390 & 1.096 \\
\hline & $p$ value & 0.004 & 0.000 & 0.036 & 0.000 \\
\hline & Odds ratio & 1.476 & 0.947 & 1.477 & 2.993 \\
\hline & $-95 \% \mathrm{CL}$ & 1.131 & 0.929 & 1.025 & 1.802 \\
\hline & $+95 \% \mathrm{CL}$ & 1.927 & 0.965 & 2.129 & 4.972 \\
\hline \multirow{6}{*}{ Social } & Constant $=1.57$ & Sex & Degree of disability & Tourist traditions in the family & Living with family \\
\hline & Beta & -0.697 & -0.666 & -1.800 & -1.637 \\
\hline & $p$ value & 0.024 & 0.010 & 0.017 & 0.000 \\
\hline & Odds ratio & 0.498 & 0.514 & 0.165 & 0.195 \\
\hline & $-95 \% \mathrm{CL}$ & 0.272 & 0.308 & 0.038 & 0.106 \\
\hline & $+95 \% \mathrm{CL}$ & 0.913 & 0.855 & 0.723 & 0.359 \\
\hline \multirow{6}{*}{ Psychological } & Constant $=-3.36$ & Education & & & \\
\hline & Beta & 0.163 & & & \\
\hline & $p$ value & 0.038 & & & \\
\hline & Odds ratio & 1.177 & & & \\
\hline & $-95 \% \mathrm{CL}$ & 1.009 & & & \\
\hline & $+95 \% \mathrm{CL}$ & 1.374 & & & \\
\hline \multirow{6}{*}{ Organisational } & Constant $=2.35-1.189$ & Place of residence & Degree of disability & Living with family & \\
\hline & Beta & -0.494 & -0.555 & -1.717 & \\
\hline & $p$ value & 0.000 & 0.003 & 0.000 & \\
\hline & Odds ratio & 0.610 & 0.574 & 0.180 & \\
\hline & $-95 \% \mathrm{CL}$ & 0.472 & 0.397 & 0.112 & \\
\hline & $+95 \% \mathrm{CL}$ & 0.789 & 0.830 & 0.288 & \\
\hline \multirow{6}{*}{ Equipment } & Constant $=-3.0$ & Car ownership & $\begin{array}{l}\text { Membership in tourist } \\
\text { organisations }\end{array}$ & Progressing disability & \\
\hline & Beta & 1.186 & 1.084 & -1.073 & \\
\hline & $p$ value & 0.008 & 0.033 & 0.007 & \\
\hline & Odds ratio & 3.274 & 2.957 & 0.342 & \\
\hline & $-95 \% \mathrm{CL}$ & 1.353 & 1.088 & 0.156 & \\
\hline & $+95 \% \mathrm{CL}$ & 7.920 & 8.036 & 0.747 & \\
\hline \multirow{6}{*}{ Architectural } & Constant $=2.99$ & Age & Degree of disability & & \\
\hline & Beta & -0.033 & -2.174 & & \\
\hline & $p$ value & 0.047 & 0.000 & & \\
\hline & Odds ratio & 0.968 & 0.114 & & \\
\hline & $-95 \% \mathrm{CL}$ & 0.937 & 0.052 & & \\
\hline & $+95 \% \mathrm{CL}$ & 1.000 & 0.248 & & \\
\hline \multirow{6}{*}{ No personnel } & Constant $=-5.69$ & Education & & & \\
\hline & Beta & 0.358 & & & \\
\hline & $p$ value & 0.007 & & & \\
\hline & Odds ratio & 1.430 & & & \\
\hline & $-95 \% \mathrm{CL}$ & 1.103 & & & \\
\hline & $+95 \% \mathrm{CL}$ & 1.853 & & & \\
\hline \multirow{6}{*}{ No travel offers } & Constant $=-5.00$ & Living with family & & & \\
\hline & Beta & 2.516 & & & \\
\hline & $p$ value & 0.014 & & & \\
\hline & Odds ratio & 12.377 & & & \\
\hline & $-95 \% \mathrm{CL}$ & 1.649 & & & \\
\hline & $+95 \% \mathrm{CL}$ & 92.888 & & & \\
\hline
\end{tabular}


The disabled with university degrees noticed psychological barriers to participation in tourism (Fig. 3).

Organisational barriers were mostly perceived by the disabled with severe disabilities, living in rural areas without their families (living alone or in nursing homes) (Fig. 4).

Equipment barriers to participation in tourism were experienced by the disabled people who drove their own cars, were members of tourist organisations, and who did not suffer from progressing disability (they had congenital disability or a disability following an injury) (Fig. 5).

Younger disabled people with severe disabilities complained about the architectural barriers to participation in tourism (Fig. $6)$.

Insufficient personnel was a barrier to participation in tourism perceived by the disabled with university degrees (Fig. 7).

The disabled living with families emphasised the lack of travel offers adjusted to the disabled as a barrier to participation in tourism (Fig. 8).

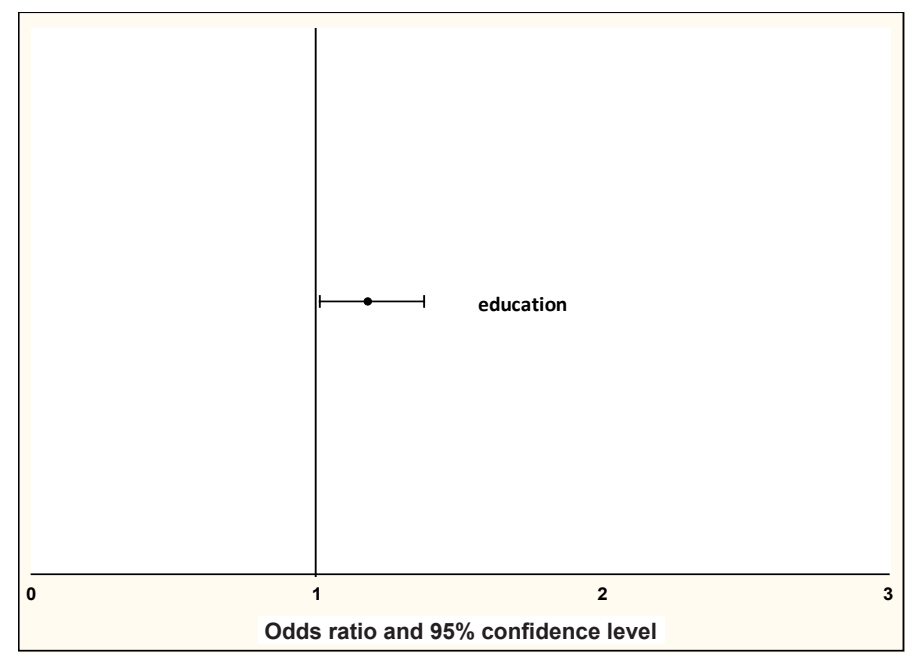

Figure 3. Psychological barriers

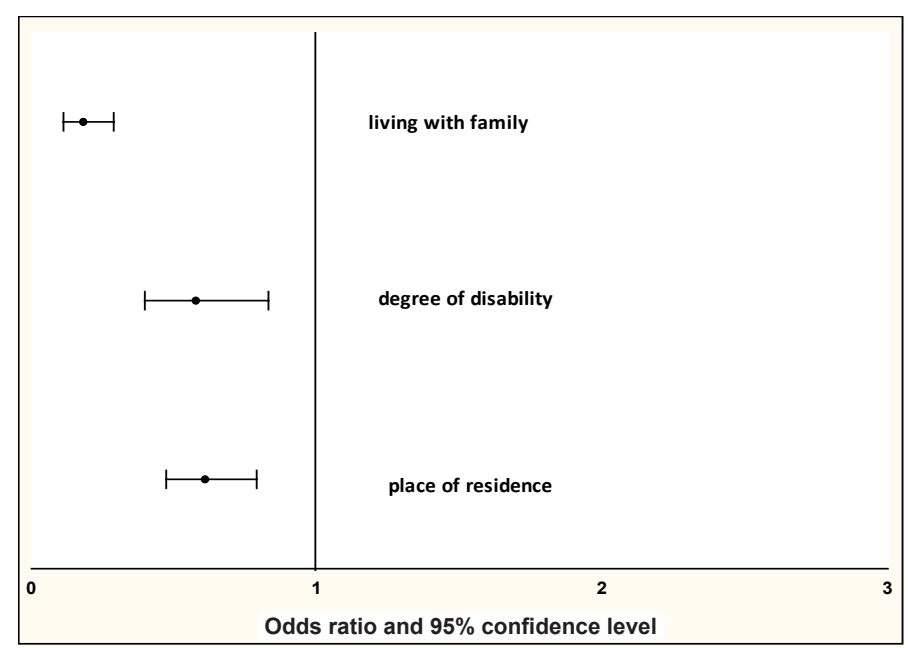

Figure 4. Organisational barriers

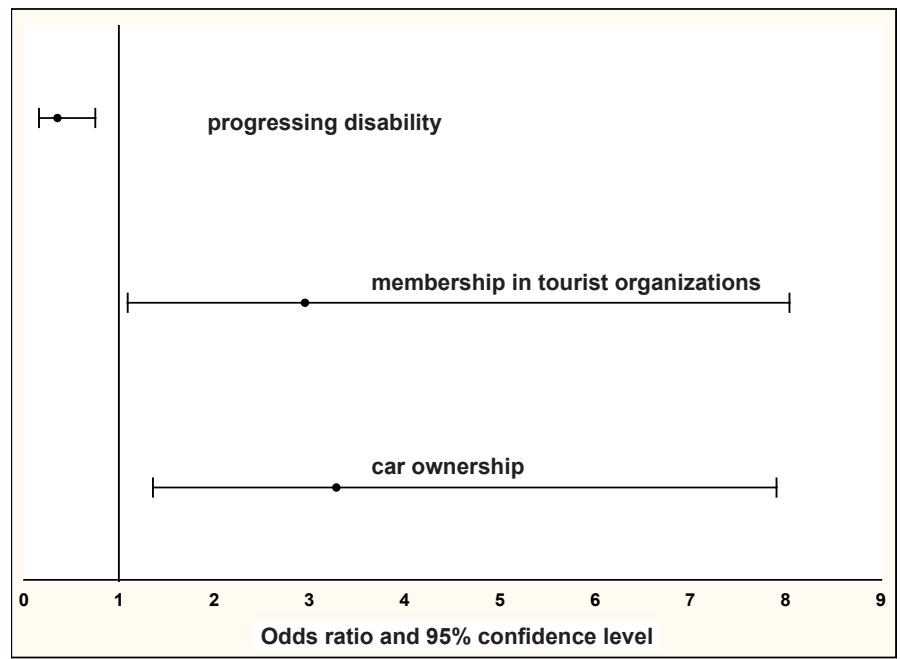

Figure 5. Equipment barriers

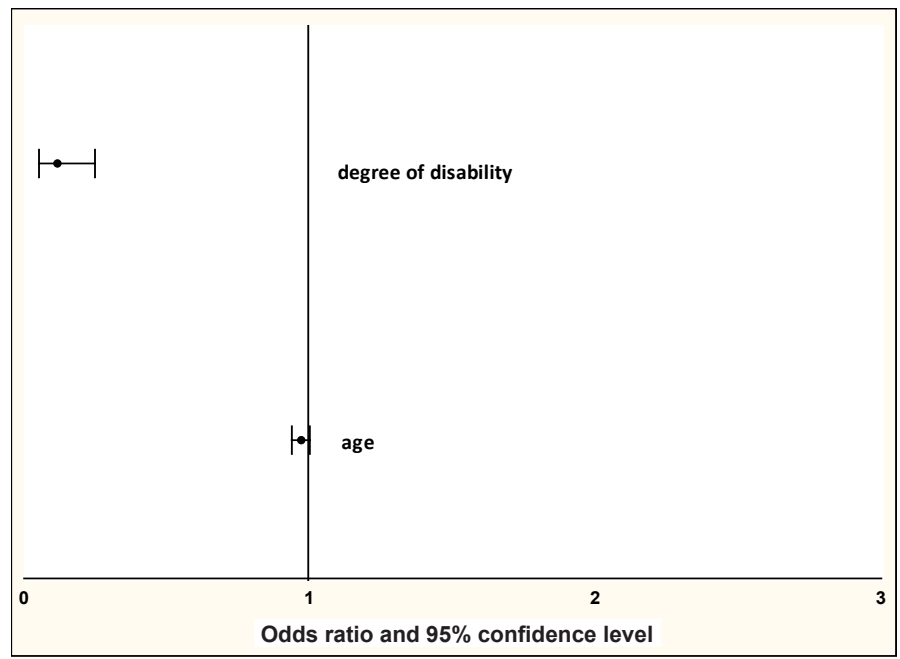

Figure 6. Architectural barriers

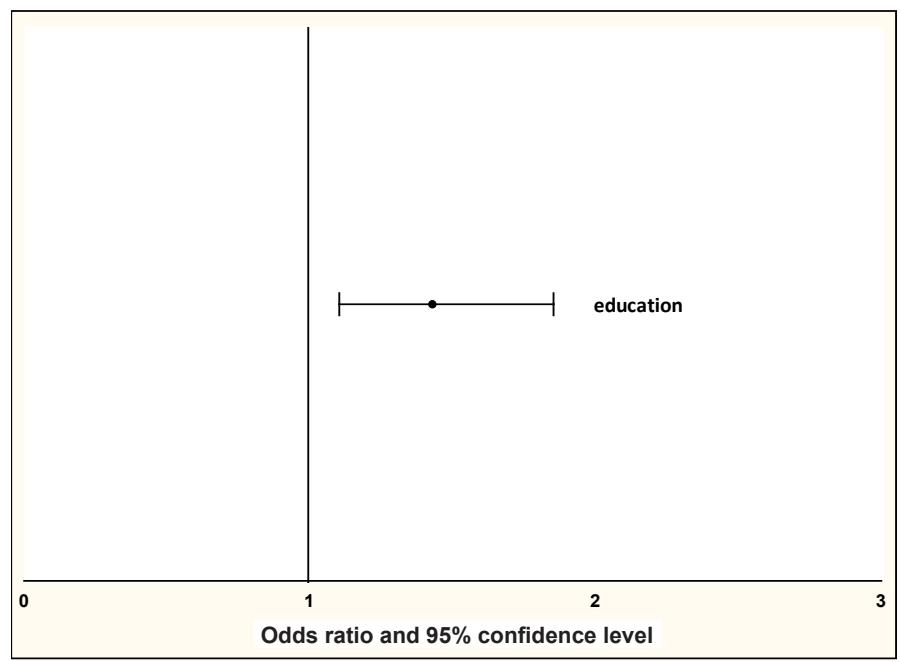

Figure 7. No personnel 


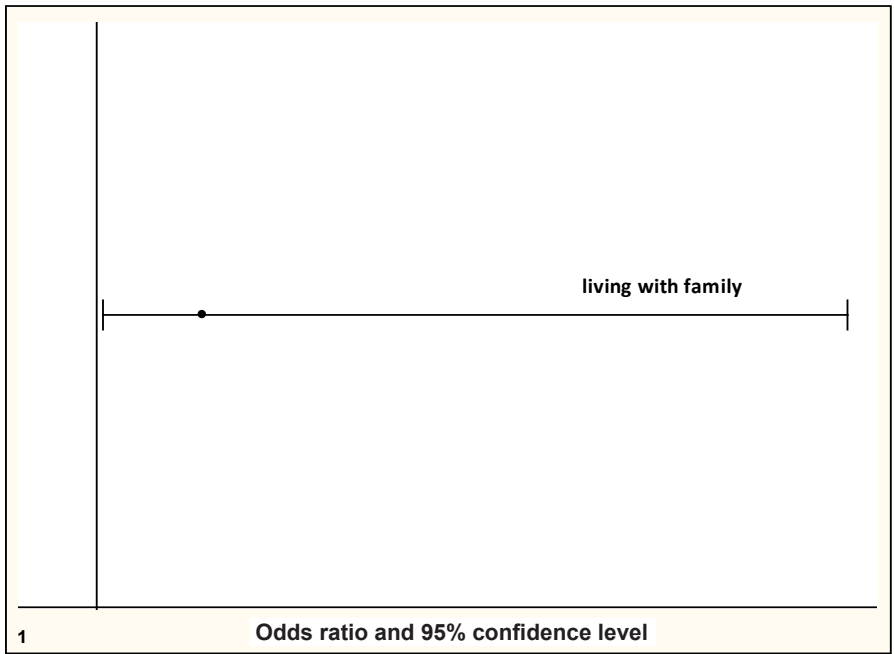

Figure 8. No travel offers

\section{Discussion}

Great Britain is an example of a country which is engaged in solving problems related to tourism among the disabled, including the barriers to participation in tourism. The introduction of the Discrimination Disability Act (DDA) in 1995 attracted substantial political and economic interest of service providers and the tourist market to the problems of the disabled [4]. This study was aimed at examining disabled people's opinions with respect to their needs. The following conclusions were drawn from the study:

- access to communication represents a critical barrier for the disabled; this mainly refers to transportation;

- the disabled can be regarded as so-called "tied tourists" since they want to travel but have limited opportunities to do so due to their disability and/or lack of resources.

The study found major barriers which the disabled have to face during holidays, such as limited access to certain destinations and financial limitations. Based on the analyses presented in the study, it needs to be stated that the main barrier to participation in tourism by the disabled people is the financial barrier. Furthermore, the research results also revealed a broader spectrum of the problems since it was focused on the determinants of particular barriers to participation in tourism. In addition to the barriers indicated by the DDA, it is also interesting how these barriers are perceived by the disabled.

An in-depth analysis of the barriers performed by the current authors, with a focus on the degree and types of dysfunction, indicated that all participants complained in general about financial barriers. Those barriers, however, affect especially young people with mild disabilities who live with their families in big cities (with more than 10,000 inhabitants).

Disabled men with severe disabilities, with no tourist traditions in the family, and not living with their families (living alone or in nursing homes) emphasised mostly social barriers. The study is consistent with the findings presented by other authors. For example, in her study, Dewine stressed that tourist and recreational activity of the disabled has been little explored as a determinant of social acceptance [5]. Her study presented different aspects of relations between social acceptance and the experience of participating in recreation in the community of the disabled. Our own research points to the importance of how social barriers are perceived.
The disabled with university degrees perceived psychological barriers to participation in tourism. Organisational barriers were emphasised by the disabled living in rural areas, those with severe disabilities, and those who did not live with their families (living alone or in nursing homes). Our study found that being a member of tourist, recreational, and social organisations makes it easier for disabled people to function with respect to participation in tourism. It should be stressed that projects related to tourism of the disabled in Poland have been implemented, among other things, by tourist and social organisations (e.g. "Tourism for Everybody" organised by the Polish Tourist and Sightseeing Society, PTTK). These organisations have access to information on buildings adapted to the needs of the disabled and buildings without architectural barriers, as well as up-todate information on the number of offers available.

The issues discussed above are also topical in Hong Kong. McKercher, Packer, Yua, and Lam state that tourist agents are largely ineffective in meeting the needs of the specialised tourist market of the disabled; agents ignore disabled people needs, which, in turn, leads to blatant or covert discrimination [6]. The aim of the research conducted by those authors was to find out if travel agents strive to make it easier for the disabled to travel.

Their findings revealed that tourist agents were incompetent in meeting the needs of the disabled. The approach to disabled tourists in Hong Kong is characterised by blatant or covert discrimination. In general, travel agents do not want to engage themselves in affairs of the disabled. Tourist offers are not sufficient and not flexible enough and inadequately adjusted, and, consequently, disabled tourists are unable to fully participate in all events and activities. A general conclusion of the research was that travel agents in Hong Kong hinder the development of tourism for the disabled. This conclusion coincides with the findings of the present study since tourist agents in Poland also tend not to meet the needs of the disabled. In particular, the disabled respondents who lived with their families regarded the insufficient number of tourist offers as a barrier to participation in tourism. A similar pattern is observed in the case of equipment barriers since there are problems with the access to the equipment adjusted to the disabled.

These observations and models used by the authors seem to be consistent with the findings presented by Cavitano and Cuckovich [7], who analysed barriers related to transport for the disabled, highlighting the necessity to strengthen investment policies in order to facilitate tourist mobility. Their final model is useful for the analysis of travelling among the disabled. However, the authors are of the opinion that it highlights problems on a macro scale, while there still is a need to reach further, to specify problems on a micro scale, that is, in elements of travelling among the disabled.

The authors of this paper had similar aims, focusing on a more thorough analysis of barriers to participation in tourism. This explains our approach to distinguishing, for example, particular types of disability. The study aim, related to barriers to participation in tourism by the disabled, was to provide knowledge and information on this topic on a micro scale. This paper refers to this micro scale by distinguishing determinants related to individual barriers, instead of simply analysing them as a whole. Such an approach helped reveal that the architectural barriers to participation in tourism are noticed by younger disabled persons with severe disabilities. Insufficient personnel were a barrier to participation in tourism perceived by the disabled with university degrees.

Apart from barriers in the strict sense, a substantial difficulty in organising tourism and recreation for the disabled is 
poor knowledge and general unfamiliarity with the problem of disability.

In one of his articles, Przectawski [8] stressed that "...to make participation in tourism available for people with special needs (the disabled), their preferred form of tourism and needs resulting from the situation of this particular group of people have to be taken into consideration". Despite the obviousness of this claim, research studies currently performed in Poland do not provide answers to the question of how this in many ways justifiable demand should be met. Similar problems are faced by other European countries, where, as Buhalis et al. [9] argued, this segment of tourism will thrive only if each group of customers is understood thoroughly.

This problem seems to be rather complex since, on the one hand, the so-called internal determinants, such as the possibility to participate in tourism resulting from specific types of dysfunction, personal aptitudes and needs, etc. have to be considered, but on the other hand, one cannot forget about external determinants, such as financial status, transport, etc.

Jones [10] holds a similar view. He attempted to make organisers of tourism for the disabled aware that the best thing they can do is to show their understanding for their customers. A comprehensive diagnosis and identification of barriers to participation in tourism and organising recreation in places friendly for the disabled are needed.

\section{Conclusions}

1. On average, the greatest and smallest numbers of barriers were reported by individuals with severe disability and those who had large families, respectively.

2. Younger disabled people most often complained about the equipment barriers to participation in tourism. Older respondents were mostly challenged with social barriers.

3. The degree of disability exerts a significant influence on the perception of financial, social, organisational, as well as architectural barriers.

4. Living with the family has an effect on the perception of financial, social, and organisational barriers and on the lack of tourist offers.
5. Of all the determinants analysed in the study, the perception of barriers to participation in tourism most often depended on the degree of disability.

\section{Literature}

1. Kwai-Sang You M., McKercher B., Packer T.L. (2004). Traveling with a disability. More than an access issue. Annals of Tourism Research 31(4), 946-960.

2. Smith R.W. (1987). Leisure of disabled tourist. Barriers to participation. Annals of Tourism Research 14(3), 376-389.

3. Kaganek K. (2009). Tourism of the disabled in light of selected determinants. Kraków: EAS. [in Polish]

4. Shaw G., Coles T. (2004). Disability, holiday making and the tourism industry in the UK: A preliminary survey. Tourism Management 25, 397-403.

5. Devine M.A. (2004). Being a doer instead of a viewer: The role of inclusive leisure contexts in determining social acceptance for people with disabilities. Journal of Leisure Research 36(2), 137-159.

6. McKercher B., Packer T., Yua M.K., Lam P. (2003). Travel agents as facilitators or inhibitors of travel: Perceptions of people with disabilities. Tourism Management 24(4), 465474.

7. Cavitano J.L., Cuckovich M.L. (1992). Transportation and tourism for the disabled: An assessment. Transportation Journal 31(3), 46-53.

8. Przecławski K. (1995). Tourism and its role vs. people with special needs. In J. Ślężyński, W. Petryński (eds.), Progress in tourism for the benefit of people with special needs (p. 34). Kraków: Polish Association of Disabled People. [in Polish]

9. Buhalis D., Eichhron V., Michopoulou E., Miller G. (2005). Accessibility market and stakeholder analysis. United Kingdom: One-Stop-Shop for Accessible Tourism in Europe (OSSATE), University of Surrey.

10. Jones S. (2004). Disabled faced by travel "barriers". Travel Weekly: The Choice of Travel Professionals 2/9/2004, 1704, 26.

Submitted: December 30, 2016

Accepted: March 27, 2017 